\title{
ON THE INTERNATIONALIZATION PROCESS OF FIRMS: A CRITICAL ANALYSIS
}

\author{
Otto Andersen* \\ Agder State College
}

\begin{abstract}
Even though international marketing has been challenged because of theoretical and methodological shortcomings, very few researchers have actually attempted to analyze the weaknesses based on principles of theory evaluation. In this article, the author examines two types of models addressing the individual firm's internationalization process. A theory evaluation is performed based on the explanation and the falsification criteria. In order to improve the internationalization models, some measures are proposed.
\end{abstract}

\section{INTRODUCTION}

More than a decade ago, Wind [1979] described international marketing as an area in which empirical work by practitioners is often more advanced and insightful than academic contributions. Recently, Ford and Leonidu [1991] have concluded that theoretical and methodological shortcomings have led to incomplete and/or inconsistent insights in the field of international marketing. A possible explanation for these shortcomings is that the academics have been too preoccupied with describing international marketing problems. As a result, little endeavour has been devoted to theory construction and evaluation. This, if true, is a phenomenon that international marketing shares with other sciences that have not reached the level of maturity in their theory development.

The internationalization process of exporting firms has been subjected to widespread empirical research (Cavusgil and Godiwalla [1982]; Dichtl et al. [1984]), and seems to benefit from a general acceptance in the literature (cf. Bradley [1991]; Reid and Rosson [1987]; Welch and Luostarinen [1988]). However, in order to secure further development and refinement,

*Otto Andersen is associate professor at Agder State College, Kristiansand, Norway. His research and publications focus on export behavior and economic and organizational analysis of small- and medium-sized firms.

Thanks to Marjo-Riitta Rynning and Sigurd V. Troye for their comments on an earlier draft of this manuscript. Thanks also to three anonymous reviewers for their helpful comments. The author is, however, solely responsible for any content and remaining errors.

Received: February 1992; Revised: July \& October 1992; Accepted: October 1992. 
the internationalization process models should be subjected to a critical evaluation.

The present article is an inquiry into two ways of describing the firm's internationalization process: (1) The models developed by Johanson, Vahlne and Wiedersheim-Paul-which will be characterized as the Uppsala Internationalization Model (U-M), and (2) The Innovation-Related Internationalization Models (I-M), focusing on internationalization as an innovation for the firm. First, a short description of each type of model will be given. Then some criteria for theory evaluation will be presented. Next, the two types of models will be discussed on the basis of these criteria. Finally, a few measures for improving the internationalization models will be discussed.

\section{THE INTERNATIONALIZATION PROCESS OF THE FIRMS}

\section{The Uppsala Internationalization Model (U-M)}

The internationalization process of the individual firm is most closely associated with the research of Johanson and Wiedersheim-Paul and Johanson and Vahlne. Their work has probably also been the inspiration for the development of the Innovation-Related Internationalization Models.

Johanson and Wiedersheim-Paul [1975] distinguish between four different modes of entering an international market, where the successive stages represent higher degrees of international involvement:

Stage 1: No regular export activites.

Stage 2: Export via independent representatives (agents).

Stage 3: Establishment of an overseas sales subsidiary.

Stage 4: Overseas production/manufacturing units.

The assumption that the internationalization of a firm develops according to a chain of establishment was originally supported by evidence from a case study of four Swedish firms. The sequence of stages was restricted to a specific country market. The entry mode literature has further developed the evolution of international supply methods, including licensing and joint venture arrangements (cf. Root [1987]).

To explain the internationalization across country markets, it was hypothezised that firms would enter new markets with successively greater psychic distance. The concept, psychic distance, has been defined as factors preventing or disturbing the flow of information between firm and market, including factors such as differences in language, culture, political systems, level of education, or level of industrial development [Johanson and Vahlne 1977, p. 24]. The firms in a study of Johanson and Wiedersheim-Paul [1975] seemed to enter new countries with successively greater psychic distance.

Johanson and Wiedersheim-Paul's work has been further developed and refined by Johanson and Vahlne [1977, 1990]. To explain the incremental 
character of internationalization, Johanson and Vahlne [1977] have formulated a dynamic model, i.e., a model in which the outcome of one cycle of events constitutes the input to the next. The main structure is given by the distinction between state and change aspects of internationalization variables. The state aspects are the market commitment (resource commitment to the foreign markets), and knowledge about foreign markets and operations. The change aspects are decisions to commit resources and performance of current business activities, a mechanism shown in Figure 1 [Johanson and Vahlne 1990, p. 12].

A basic assumption is that market knowledge and market commitment affect both commitment decisions and the way current decisions are performed-and these, in turn, change market knowledge and commitment.

The concept of market commitment is assumed to be composed of two factors - the amount of resources committed and the degree of commitment. The amount of resources could be operationalized as the size of investment in the market (marketing, organization, personal, etc.), while the degree of commitment refers to the difficulty of finding an alternative use for the resources and transferring them to the alternative use. The latter concept seems to be close to the concept of sunk cost.

International activities require both general knowledge and market- specific knowledge. Market-specific knowledge is assumed to be gained mainly through experience in the market, whereas knowledge of the operations can be transferred from one country to another; the latter will thus facilitate lateral growth. A direct relation between market knowledge and market commitment is postulated: Knowledge can be considered as a dimension of human resources. Consequently, the better the knowledge about a market, the more valuable are the resources and the stronger the commitment to the market. This is assumed to be especially true of experiential knowledge.

Johanson and Vahlne [1977] state that current business activities are the prime source of experience. The commitment decisions are concerned with decisions to commit current resources to foreign operations. Assuming that these decisions are made in response to perceived problems and/or opportunities in the market, the commitment decisions will depend on experience and will be related to the operations currently performed in the market.

Following Johanson and Vahlne [1990, p. 12], Figure 1 implies that additional market commitment as a rule will be made in small incremental steps. There are, however, three exceptions. First, firms that have large resources experience small consequences of their commitments and can take larger internationalization steps. Second, when market conditions are stable and homogeneous, relevant market knowledge can be gained in ways other than experience. Third, when the firm has considerable experience from markets with similar conditions, it may be able to generalize this experience to any specific market. 
FIGURE 1

The Internationalization Process of the Firm

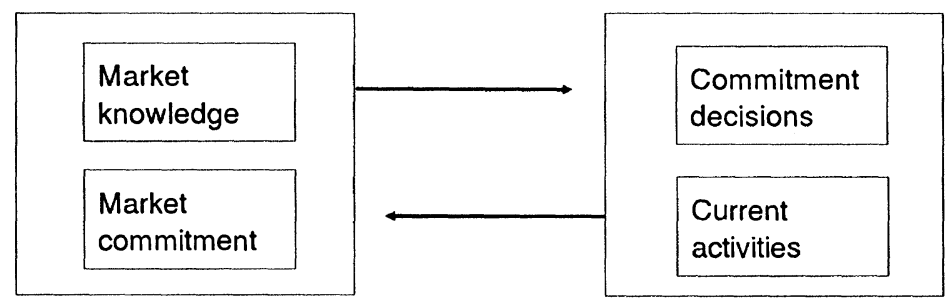

\section{The Innovation-Related Internationalization Models (I-M)}

Figure 2 summarizes the most well-known models explaining the internationalization process from an innovation-related perspective.

The models in Figure 2 focus on the learning sequence in connection with adopting an innovation. In other words, the internationalization decision is considered as an innovation for the firm. The models are derived from Roger's stages of the adoption process [Rogers 1962, pp. 81-86].

The models in Figure 2 share many features. The main differences are in the number of stages and the description of each stage. The incentives to start exporting, for example, seem to be interpreted differently in the models of Bilkey and Tesar [1977] and Czinkota [1982], vs. the models of Cavusgil [1980] and Reid [1981], respectively. The two former presume that the firm is not interested in exporting at Stage 1, and is willing to fill unsolicited orders/is partially interested at Stage 2, which makes it reasonable to believe that there must exist some kind of "push" mechanism or external change agent that initiates the export decision. In the two latter models, the firm is described as a unit more interested and active during the early stages. In these models, a "pull" mechanism or internal change agent is probably a more relevant explanation as to why the firm moves to the next stage. Except for the initiating mechanism, the differences between the models seem to reflect semantic differences rather than real differences about the nature of the internationalization process.

Both the U-models and the I-models can properly be regarded as behaviorally oriented. Based on the arguments by the authors, the gradual pattern of the firm's internationalization process can mainly be attributed to two reasons: (1) The lack of knowledge by the firm, especially "experiential knowledge," and (2) Uncertainty associated with the decision to internationalize. The arguments for the gradual pattern are discussed in length in the article of Johanson and Vahlne [1977]. The other authors explicitly or implictly build on Johanson and Vahlne's contribution. 


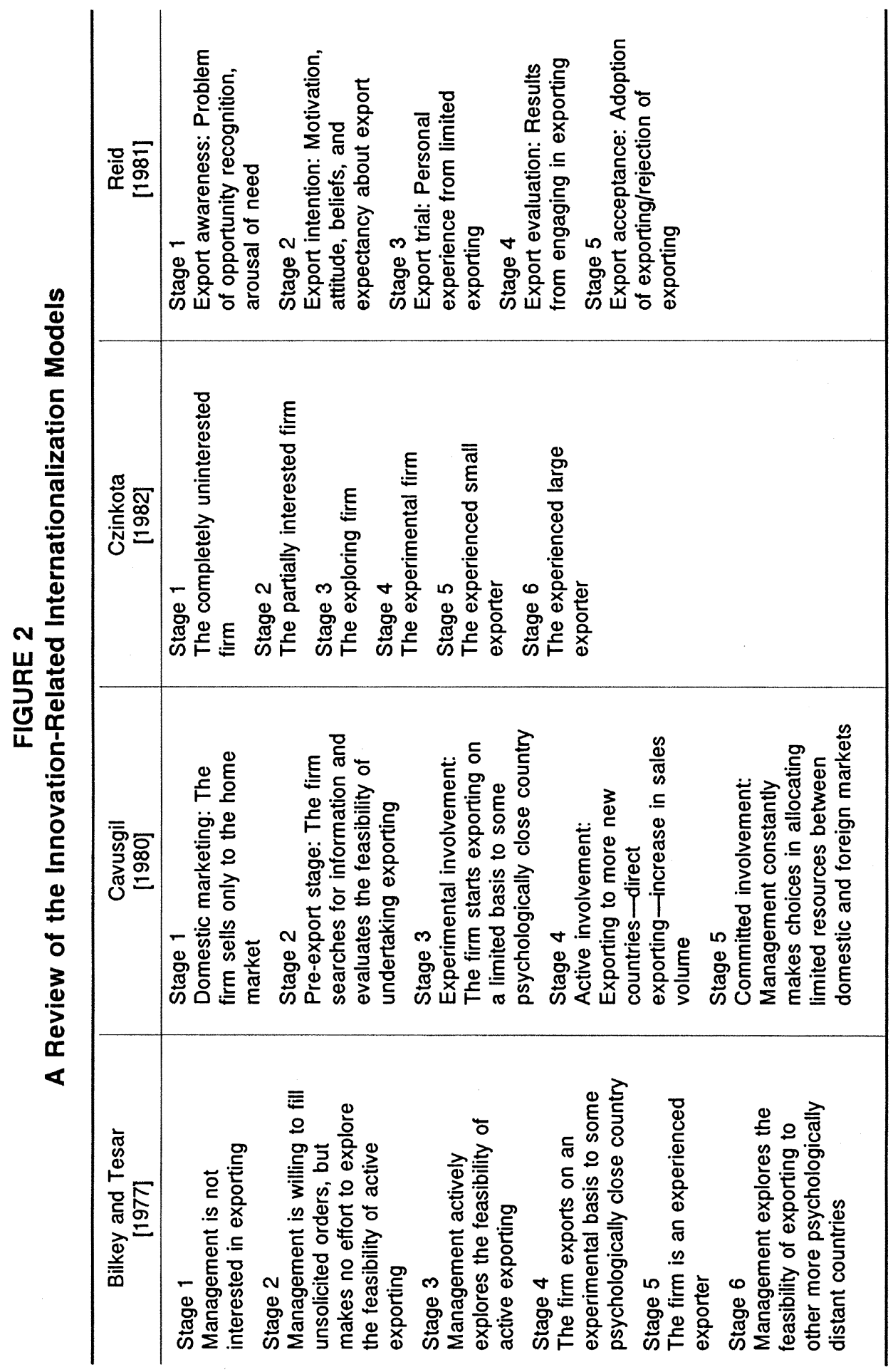




\section{SOME CRITERIA FOR EVALUATION}

\section{The Notion of Theory and Models}

Before discussing the criteria that will be used, I will briefly discuss the notion of theory and models. Even among the philosophers of science, the term "theory" has been defined in various ways (for a review, see Zaltman et al. [1973, p. 76]). These differences reflect different uses of the term theory, or illustrate the possibility of looking at theories from various points of view. In this article, I have chosen the well-known definition of Kerlinger [1973, p. 9]: "A theory is a set of interrelated constructs (concepts), definitions, and propositions that presents a systematic view of phenomena by specifying relations among variables, with the purpose of explaining and predicting the phenomena." The definition is normative, as it states that a theory should include definitions of concepts, the propositions should be consistent among themselves and should present a systematic view.

The distinction between theory and model is not very clear. Rigby [1965, p. 109] suggests that a model is any structure that purports to represent something else. Thus, a model has to be related to something else, i.e., to some phenomena. Following Hunt [1991a, p. 50], all theories are models, since all theories purport to represent some aspects of real-world phenomena. However, the converse is not true; all models are not theories since many models will not have all the prerequisites of theoretical constructions. A theory may be represented by various models, particularly if the concepts contained in the theory are abstract.

\section{Generation of Criteria for the Evaluation}

It is hard to imagine that a theory could be evaluated to be entirely satisfactory by all criteria. The large number of different criteria that can be specified (see, for instance, Dodd [1968], in Zaltman et al. [1973]) makes a complete evaluation of a theory impossible. The choice of criteria cannot be objectively determined, but will largely depend on what the evaluator believes are important aspects of a theory. Below, I will give some arguments for my choice of criteria. Even though only a few criteria will be used, these criteria can be characterized as broad, in the sense that they partially incorporate other criteria.

The Type of Explanation. Explanation plays an important role in a theory. As opposed to descriptive research which is preoccupied with the question of what, an explanation is an answer to a why question. However, any explanation is not necessarily a scientific explanation; an objective here should also be to answer the questions of how and when. A scientific explanation establishes the substantive meaning of nonobservational and observational variables and their linkages.

A scientific explanation gives a frame of reference for classifying various theoretical contributions, which is convenient for the succeeding evaluation. 
Models of explanation can be categorized into four types: (1) The deductivenomological, (2) the probabilistic model, (3) the functional or teleological model, and (4) the genetic model [Zaltman et al. 1973, p. 131]. These various kinds of explanatory models employ fundamentally different kinds of logic and evidence to explain phenomena. When analyzing a theory or model, it is imperative to state the boundary assumptions. These assumptions set the limits in applying the theory, and thus point out under which circumstances (for instance, time and objects) the theory should be used as an explanation. Another type of classification is between causal and noncausal explanation. Even though utility often is handled as a specific criterion, the utility of the explanation will also be discussed.

Accordingly, the explanation criteria include a wide range of central characteristics to describe and classify the model (or theory), which may give insight into what the model really represents.

The Falsifiability Criterion. Among the philosophers of science, Popper [1959] has been the most explicit and systematic proponent of recognizing the need for basing scientific knowledge on ruling out alternative explanations of phenomena so as to remain with only one conceivable explanation.

Popper uses falsifiability as a criterion of demarcation to distinguish science from nonscience, when he declares that " A statement (a theory, a conjecture) has the status of belonging to the empirical sciences if and only if it is falsifiable" [Popper 1983, xix]. This view is an asymmetry compared to the logical positivists, who initially chose verifiability (or a confirmatory approach) as their criterion of cognitive significance, that is, a synthetic statement is meaningful, if and only if it is capable of being empirically verified. However, as argued by Sternthal et al. [1987], it is impermissible to reason inductively from the successful predictions of a theory to its truth content: "The goal of the confirmatory approach cannot be realized because theories cannot be proven"' (p. 124).

In marketing as well as in other disciplines, there is by no means a consensus among scientists whether the falsifiability criterion should be used (e.g., Anderson [1986], Calder and Tybout [1987], Hunt [1991a,1991b], Peter and Olson [1983]). However, in judging theories, the falsification methodology manifests a Humean skepticism (cf. Hunt [1992]) that should be valuable in itself. Furthermore, a distinction should be made between the use of theory falsification procedures when constructing and evaluating a theory, and the decision to reject or accept a theory. While the disagreement may be strong concerning the second topic, the aspects of the first issue, which will be focused on in this paper, should be more widely accepted.

When using theory falsification procedures, the abstract theoretical explanation must be rendered fully testable. This implies that the nature of the constructs and the relationship between them should be clearly defined and specified, and nontautological. Furthermore, it involves making certain that 
there is a high degree of correspondence between the empirical operationalizations and the abstract concepts they intend to represent, and that the empirical indicators used to represent the theory's constructs cannot be construed in terms of other constructs. This is necessary to ensure that corroboration/disconfirmation of a theory is not due to empirical operationalizations not measuring the theoretical concepts and, thus, not testing the relationship of interest (cf. Calder et al. [1981]). Even though falsification procedures embrace other methodological issues, this paper will focus on points mentioned above.

Both the explanation and falsifiability criteria are quite broad in the sense that they are highly dependent on other attributes of a theory, such as generalizability, empirical interpretability, and utility. Thus, the explanation and falsifiability criteria will here be used in the sense of "super-criteria."

\section{THE EVALUATION}

In this section, a parallel evaluation will be made for the two types of models (the Uppsala Internationalization Model, and the Innovation-Related Internationalization Model), which will provide an opportunity to compare the strengths and weaknesses of the models. I will start with the explanation criterion and continue with the falsifiability criterion.

\section{The Internationalization Models from an Explanatory Perspective}

Type of Scientific Explanation. Both the Uppsala Internationalization Model (U-model) and the Innovation-Related Internationalization Models (I-models) are based on a behavioral approach, regarding internationalization as a process. The U-model, with its emphasis on learning theory, is presented as a dynamic model, while the I-models portray the internationalization process as a step-by-step development.

Both types of models may be characterized as genetic or historicist explanations. The explanation of a particular state or condition is based on some prior state or a sequence of some prior states (cf. Zaltman et al. [1973, pp. 133-34], and Stinchcombe [1968, p. 103]. A central task of genetic explanations is to determine the sequence of states. Furthermore, the explanatory depth is dependent on the degree that a model can explain the factors that will trigger a move from one state to the next.

Concerning the U-model, Johanson and Vahlne [1990, p. 17] state that the "aim is ... to contribute to an understanding of the incremental nature of the internationalization process." No initial conditions are presented, i.e., the model does not explain why or how the process starts, and the sequence of states or conditions is not discussed. The core explanation of the model is that (increased) market knowledge will lead to (increased) market commitment, and vice versa. However, based on the definition of market commitment (the amount of resources committed), and the fact that market knowledge 
could be regarded as an intangible resource, the explanation above is in fact tautological. Furthermore, the authors do not discuss factors that may influence the process, as they expect that "the internationalization process, once it has started, will tend to proceed regardless of whether strategic decisions in that direction are made or not" (p. 12).

The I-models are represented by stages (see Figure 1), where a higher level stage represents more experience/involvement than the lower level stages(s). The models are mainly composed of nonobservable concepts. Generally, this makes it difficult to delimit the stages. The sequence of stages is open to the same type of criticism as the adoption process models in consumer behavior (see, for example, Robertson [1974]), i.e., it can be argued that firms actually do not or should not follow the stages in the presented sequence (see also Reid [1983]; Turnbull [1987]). As noted above, the sequence will depend-among other things—on the assumptions concerning the initiative of the process (cf. 'pull' vs. 'push' mechanism).

As presented in Figure 2, the various chains of explanation are intuitive logic axiomatic, and close to being trivially obvious. However, several of the authors have tried to explain in more detail the characteristics of each stage, and, more importantly, to explain the movement from one stage to the next (see Bilkey [1978]; Cavusgil [1982; 1984]; Reid [1981]). As noted by Bilkey [1978, p. 40-41], the huge number of variables that influence the export behavior of firms implies an important problem in predicting moves. The crux of this problem is in the lack of a proper theory. The empirical tests of the I-models will be examined under the falsifiability criterion.

Boundary Assumptions. Implicitly or explicitly, all theories have a set of boundary assumptions and constraints, which delimit the application of the theory. Perhaps the most important assumptions relate to space and time. Spatial boundaries are conditions restricting the use of the theory to specific units of analysis (e.g., specific types of organizations), while temporal contingencies specify the historical applicability of a theoretical system [Bacharach 1990, pp. 499-500]. Spatial and temporal boundaries under one restrict the empirical generalizability of the theory. Some theories may be bounded in time, but relatively unbounded in space-and vice versa.

For instance, the I-models should apply from the time (or immediately preceding) the idea of exporting is initiated until that international activities are regarded as an ordinary and accepted part of the firm's activities. The theoretical explanation of U-models seems to be unbounded in time.

Concerning space, the delimitation is less clear. Reid [1981, pp. 101-102] points out the need to make a distinction between the foreign entry expansion process in small and large firms. Considering small firms, the export behavior is assumed to be influenced by the individual decisionmaker(s), while the entry behavior in large firms is supposed to be structurally determined. Cavusgil [1982] maintained that one explanation for the sequential 
nature of the internationalization process may be provided by the decisionmaking dynamics of especially smaller firms. Bilkey and Tesar [1977] conclude that the "stages" model is meaningful for examining export behavior particularly of small- and medium-sized firms. Thus, it seems that firm size represents a boundary assumption for the I-models. On the other hand, Johanson and Vahlne [1990] present no restrictions on the units of analysis. They notice, however, that large firms can be expected to take larger internationalization steps than small firms.

As a tentative conclusion, the U-model seems to be less bounded in both space and time, and can thus be expected to have a higher level of generalizability than the I-models. This generalizability requires a higher level of abstraction, which means that the level of precision is being traded off.

Several theories have been proposed to explain the choice of foreign entry modes by firms. Dunning's eclectic explanation [Dunning 1988] and the transaction cost explanation [Anderson and Gatingnon 1986; Caves 1982; Gatignon and Anderson 1988; Hennart 1982; Rugman 1982] are probably the best-known explanations. According to Dunning, the firm's decision to enter a foreign market and the choice of entry form depend on its ownershipspecific advantages, internalization-specific advantages, and location-specific advantages. Anderson and Gatignon [1986] treat the choice of entry modes from the perspective of choosing the degree of vertical integration of international business. The alternatives run from contractual entry modes to full integration and, between these two extremes, intermediate modes of entry. Both the eclectic paradigm and the transactions cost approach contribute to a more complete explanation of the firm's foreign operations than the entry modes model of Johanson and Wiedersheim-Paul [1975]. These theories are, however, probably more relevant at the later stages of the internationalization process.

Causal versus Non-Causal Explanation. Zaltman et al. [1972] argue that there are at least four levels of understanding an explanation in the behavioral sciences. To be a candidate for a causal explanation, the explanation must at least pass level two: "The phenomenon is of the nature $Q$ and is produced by factors $x_{1}, x_{2}, x_{3}, \ldots$ ', (p. 129). The interpretation of cause varies by philosophers of science (cf. Cook and Campbell [1979, pp. 10-30]). To infer causality, research textbooks often use the following three criteria (see, for instance, Simon [1978, pp. 341-53]): (1) Associative variation, (2) Temporal sequentiality, and (3) Nonspurious association. Theoretical support should also be included in the evaluation of a causal statement (cf. Hunt [1991a, pp. 86-89]).

The U-model describes the internationalization process as causal cycles (Johanson and Vahlne [1990, p. 11]), i.e., market knowledge and market commitment are assumed to affect commitment decisions and current activities, which, in turn, are affected by market knowledge and market commitment. However, later on the authors state that the firm's knowledge 
is the only explicit explanatory variable (p. 17). No explanation is presented concerning how the process will start, or the nature of the mechanism whereby knowledge affects commitment. In addition, even though all explanations are incomplete, it can be argued that only one explanatory variable seldom can provide a sufficient explanation.

The explanation chains of the I-models provide a clearer understanding of the assumed sequence or time order of the internationalization process. As noted above, the chains do not by themselves explain or predict the movement from one stage to the next. Looking at, for instance, the model of Cavusgil [1980], Stage 1 (domestic marketing) cannot explain why a firm moves to Stage 2 (pre-export stage), even if Stage 1 logically precedes Stage 2. Some of the I-models have used a large number of basically organizational variables to explain the movement from one stage to the next. These attempts will be commented on later in the evaluation from a falsifiability perspective.

Utility of Explanation. The utility of an explanation will depend on who is judging and his/her standards of value. The usefulness of both the U-model and the I-models for management and government has been emphasized (see, for instance, Bilkey [1978]; Cavusgil [1980]; Johanson and Vahlne [1977]). The usefulness of a theoretical contribution will, of course, increase when the results can be applied. However, a distinction should be made between the contribution to an intuitive understanding and a scientific understanding (Bunge [1967, pp. 30-31]). Obviously, few practitioners will deny the idea of internationalization as a process, and many will probably find the models to be psychologically comfortable. However, an intuitive understanding does not imply scientific understanding. In this section, some aspects of the utility of a scientific explanation will be discussed.

Specificity of the assumptions about the objects of analysis, many relevant variables properly defined and providing precise statements of the relations between antecedent and consequent, are considered to make a more powerful contribution to a scientific understanding than an explanation without these characteristics.

Among assumptions about the objects, the size of the firms has already been discussed. The U-model and I-models seem to lean on assumptions about the firms' behavior that dominated the literature in the 1960s (e.g., Cyert and March [1963]), while later theories such as the eclectic paradigm and transaction cost analysis to a higher degree incorporate the influence of the market side and regard the decisionmaker as strategically more conscious. The innovative nature of the early stages of the internationalization process is, however, an argument for assuming a disjointed, incremental decisionmaking process (cf. Braybrooke and Lindblom [1970]; Cavusgil and Godiwalla [1982]).

The concepts in the U-model are not defined. Instead, some possible indicators are presented. Lack of proper definitions makes it difficult to specify the 
necessary and sufficient conditions in the model, and the nature of causal linkages. In the I-models, efforts have been made to specify variables and operationalizational definitions for the stages involved and variables that influence the process. The arguments for classification procedures and for operationalization of explaining variables are, however, quite vague.

Figure 3 presents a short summary of the evaluation from an explanatory perspective.

\section{THE INTERNATIONALIZATION MODELS FROM A FALSIFIABILITY PERSPECTIVE}

The falsifiability of a theory is obviously highly dependent upon other attributes, such as empirical interpretability and precision. To ensure empirical interpretability (or testability), the theoretical concepts must be properly defined and the relationships between the concepts must be clearly specified. Moreover, operational definitions connecting the empirical-observational level intimately to the conceptual-theoretical level should be presented. There should be a high degree of congruence between the conceptual and empirical level, between the conceptual definitions and operational definitions, i.e., falsification procedures should be established [Calder et al. 1981].

\section{The U-Model}

According to Johanson and Vahlne [1990, p. 13], the model in Figure 1 can explain both the pattern of the chain of establishment in a specific country market, and the empirical pattern according to which those firms enter new markets with successively greater psychic distance. The authors characterize the process in Figure 1 as a theoretical model, while the establishment chain and the psychic distance model represent operationalizations of the theoretical model. This statement is illustrated in Figure 4.

The relationships between the concepts of the theoretical model are quite vague; some of them are in fact nondirectional. Vaguely specified relationships make it difficult to test the model from a falsifiability perspective. The congruence between the theory level and the operational level will nevertheless be discussed in the following.

Concerning operationalization (1)-the establishment chain within a specific country-Johanson and Vahlne state that the sequence of stages indicates an increasing commitment of resources to the market. Furthermore, it is supposed to indicate that current business activities differ with regard to the market experience gained (p. 13). Thus, it seems that concepts from theory level have been used to explain and hypothesize about the establishment chain at the operational level. This procedure is not, however, sufficient to secure congruence between the theoretical and operational level. Let us suppose that the results from a survey are positive, i.e., that the development within a country follows the establishment chain. Is it then justified to 
FIGURE 3

A Summary of the Evaluation Based on the Explanation Criteria

\begin{tabular}{|c|c|c|}
\hline Aspects Evaluated & U-Model & I-Models \\
\hline $\begin{array}{l}\text { Type of scientific } \\
\text { explanation }\end{array}$ & Genetic (historicist) & Genetic (historicist) \\
\hline $\begin{array}{l}\text { Boundary assumptions } \\
\text { - Space (units of analysis) } \\
\text { - Time } \\
\text { Causality } \\
\text { - Model type } \\
\text { - Explanatory variables } \\
\text { (process development) }\end{array}$ & $\begin{array}{l}\text { No specified restrictions } \\
\text { Unbounded } \\
\text { Causal cycles } \\
\text { One variable: Firms' } \\
\text { knowledge }\end{array}$ & $\begin{array}{l}\text { Small- and medium-sized firms } \\
\text { Bounded } \\
\text { Explanation chains } \\
\text { Many different, most } \\
\text { organizational characteristics }\end{array}$ \\
\hline $\begin{array}{l}\text { Utility - scientific } \\
\text { - Assumptions about firms' } \\
\text { behavior }\end{array}$ & \multicolumn{2}{|c|}{$\begin{array}{l}\text { Based on behavioral theories, incremental decision- } \\
\text { making process, with little/no influence from competitive } \\
\text { and market factors. }\end{array}$} \\
\hline - Variables properly defined & $\begin{array}{l}\text { Examples of possible } \\
\text { indicators, no operational } \\
\text { definitions }\end{array}$ & $\begin{array}{l}\text { Unclear arguments for } \\
\text { classification procedures, } \\
\text { and for operationalization of } \\
\text { explaining variables }\end{array}$ \\
\hline $\begin{array}{l}\text { - Precise statements of the } \\
\text { relations between stages }\end{array}$ & Considerable vagueness & Basically intuitive arguments \\
\hline Utility---intuitive & \multicolumn{2}{|c|}{$\begin{array}{l}\text { Logic axiomatic. The usefulness is stressed for } \\
\text { management and governments }\end{array}$} \\
\hline
\end{tabular}

conclude that the theoretical model is corroborated? Similarly, if the results were negative, could we then falsify the theoretical model? In my opinion, the answer to both questions is no, and the reason is that clear linkages between the theoretical and operational level are missing.

The second pattern predicts that firms enter new markets with successively greater psychic distance (see operationalization 2 in Figure 4). Johanson and Vahlne [1975] assume that even if psychic distance is not constant, most changes will take place rather slowly. However, when a firm has chosen a foreign market, the psychic distance to that market is assumed to be reduced due to increased market-specific knowledge. Furthermore, if knowledge of transactions can be transferred from one country to another, firms with an extensive international experience are likely to perceive the psychic distance to a new country as shorter than firms with little international experience. Accordingly, the operationalization (2) should be restricted to predict a specific firm's choice of a new market early on. Besides the lack of congruence between the theoretical and operational level, the boundary assumptions of operationalization (2) seem to be more restricted than assumed at the theory level. The establishment chain within a specific country has also been suggested in the entry mode literature (cf. Root [1987]). Empirical support for such an evolutionary path has been found in several studies (e.g., Buckley et al. 
FIGURE 4

The Theoretical and Operational Level of the U-Model

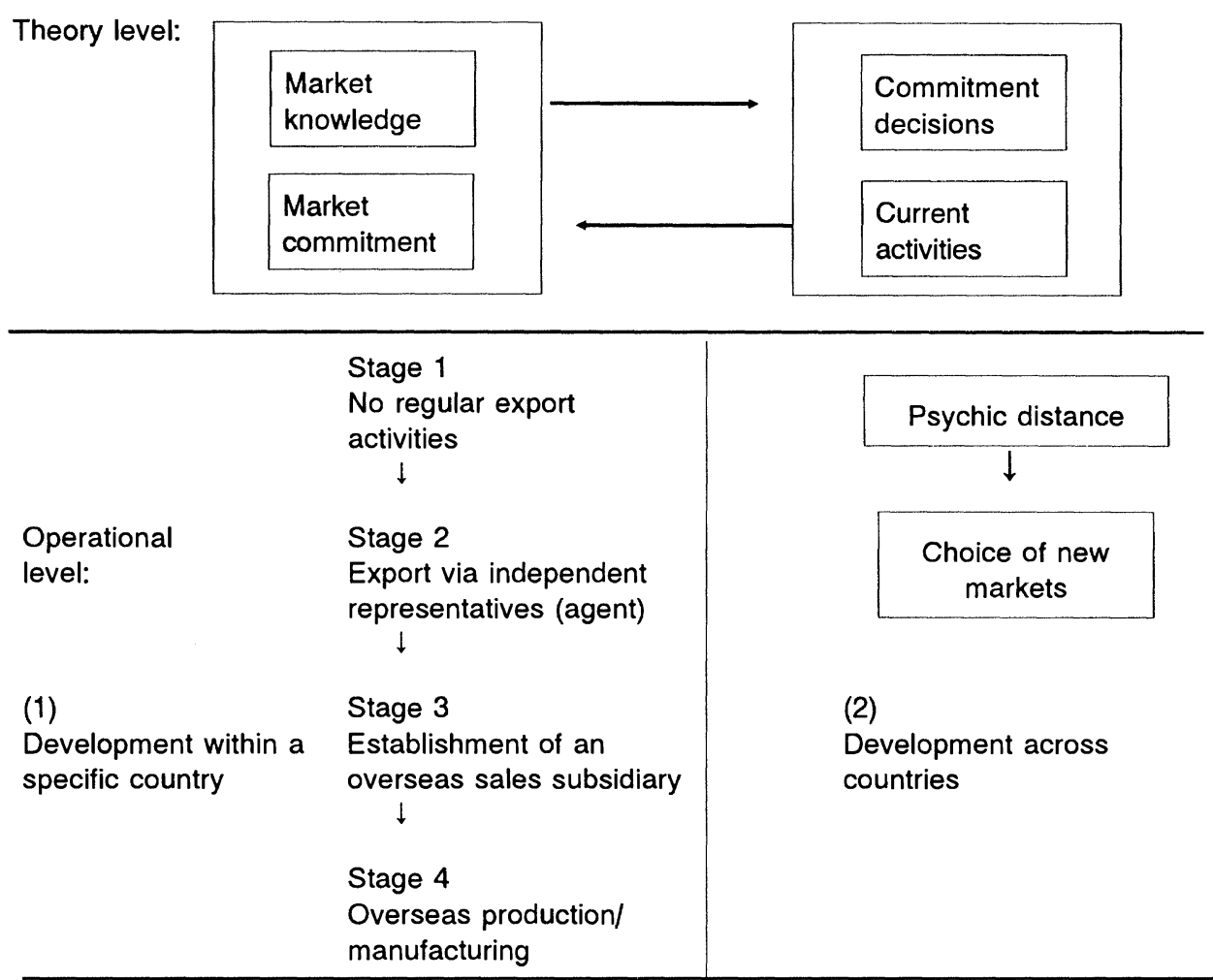

[1979]; Luostarinen [1979]). However, among other studies there is little support to the establishment chain hypothesis (cf. Ayal and Raben [1987]; Turnbull [1987]). It has been argued that the choice of export mode will depend on several factors, including the foreign market opportunity, the firm's resources, the type of product, and product life cycles (Rosson and Reid [1987]; Young et al. [1989]).

Concerning the choice of new markets, a systematic approach based on country/market screening methods has been suggested even for small- and medium-sized enterprises (e.g., Douglas et al. [1982]; Papadopoulos [1987]). However, there is ample evidence that the majority of SMEs in the early stages of internationalization do not approach the international market selection systematically [Papadopoulos and Denis 1988]. The hypothesized relationships between psychic distance and choice of new market were not confirmed in a study of European forest products firms [Sullivan and Bauerschmidt 1990], nor in cases of market selection involving direct investment [Engwall and Wallenstål 1988; Benito and Gripsrud 1991].

To conclude, the empirical research has given mixed support to the operationalized models in Figure 4. For reasons of space, a more complete discussion 
of the studies cannot be presented here. However, the empirical studies differ with respect to operationalization of key variables, selection of research settings and designs. From a falsifiability point of view, it can be argued that more precise statements of the boundary assumptions of the modelsi.e., identifying under which circumstances the models should be relevantare needed in order to develop appropriate empirical testing methods.

\section{The I-Models}

In this section, I will comment on the work of Bilkey and Tesar [1977], Cavusgil [1980, 1982] and Czinkota [1982]. Other empirical works illustrating the differences between exporters and non-exporters (exporter profiles), and I-models based on case studies will not be examined.

The study of Bilkey and Tesar [1977] is based on a randomly drawn sample $(n=816)$ of small- and medium-sized Wisconsin manufacturing firms. A mail questionnaire resulted in a response rate of 52\%. Cavusgil's [1982] study is a mail survey among a systematically selected group of manufacturing firms in Maine and New Mexico (neither the number of respondents nor the response rate have been reported). The population in the study of Czinkota [1982] is based on three industries, consisting of small- and medium-sized independent firms manufacturing industrial goods. The questionnaire had been sent to all firms that met the criteria and resulted in a net response rate of $24 \%$ (237 questionnaires). It should be noted that most studies of the I-models are restricted to small- and medium-sized manufacturing firms, and the use of a cross-sectional design. The firms are classified into various stages according to one or a few characteristics of their international activity or involvement.

The classification procedure, which is defined by the operationalization of the stage concepts, is a critical issue. In general, we may distinguish between at least two interpretations of a process model: (1) A continuous process, and (2) A discontinuous process, where the stages are disjunctive. Apparently, the I-models assume a discontinuous process. However, some problems may arise in establishing classificational procedures that are intersubjectively unambiguous (cf. Hunt [1991a, pp. 183-89]). For instance, is it possible to decide when a firm leaves Stage 4 (active involvement) and moves to Stage 5 (committed involvement) in the Cavusgil model?

The use of cross-sectional studies precludes studies of the moves by an individual firm from one stage to the next, because a change in the level of involvement for a firm at one stage will automatically lead it (by classification) to the next stage. To establish a chain model, a longitudinal design should be used. This would make it possible to study the changes of other variables that may explain a move from one stage to the next. In a longitudinal analysis, the problems of establishing demarcation lines between stages could, in principle, be captured by different variables measuring time-dependent factors. 
Cavusgil's Study. Cavusgil [1982], using a somewhat different description of the first three of the five stages than in his earlier work (see Figure 1), ended up with the following four stages at the operational level:

Stage 1: Nonexporting firms, not interested in gathering exportrelated information.

Stage 2: Nonexporting firms, interested in gathering export-related information.

Stage 3: Exporting firms. Export less than $10 \%$ of their output.

Stage 4: Exporting firms. Export more than 10\% of their output.

Cavusgil did not give reasons for the modification of his earlier theoretical model, nor did he argue for the differences in the number of stages or for the description (choice of criteria/operationalization) of the stages included. This makes it difficult to reach a conclusion that the empirical results corroborate the theoretical model.

In order to explain firms' progression over the internationalization process, Cavusgil presented a list of seventeen variables. Except for one variable (firm size), all variables turned out to have a significant impact (using univariate $F$-test) when measuring moves from one stage to the next; seven variables were also significant for "two movements." There is no information about the degree of heterogeneity of firm size in the sample. No intercorrelation matrix is presented.

It is hard to characterize Cavusgil's results as unexpected. For instance, information seeking on exporting from external sources provided significant results both for progression from Stage 1 to Stage 2, and also from Stage 2 to Stage 3. At least for the first movement, this should follow from the operationalization of the "explanatory" variable. The finding that the firms' local market orientation decreases when they move from Stage 2 to Stage 3 and from Stage 3 to Stage 4, should not be surprising when this variable is measured as the firm's share of sale in the state, and cannot without reservation be used to support Welch and Wiedersheim- Paul's [1980] hypothesis on the firms' extraregional expansion. The findings that managers of Stage 2 are more likely to be younger and more educated compared to Stage 1, should follow from the rich literature and empirical findings about individual characteristics of information seekers.

However, some "unexpected" results are reported: The firms at Stage 3 perceived greater risk and lesser profits in exporting than the firms at Stage 2. According to Cavusgil, a possible explanation is that "these firms are relatively new on exporting, finding themselves confronted with a number of unexpected hurdles." This statement illustrates a central point of the study: The variables cannot predict movements from one stage to the next; it is only possible to characterize the firms that have been classified into different stages. Thus, Cavusgil's explanation that initial involvement is less likely to be brought about by purely economic motivations, should be confronted 
with an alternative explanation: The firms at Stage 3 may have lower profits because of the export involvement. Therefore, they may perceive the risk to be higher.

To summarize, there are discrepancies between the theoretical and operational level, with serious implications for the possibility of falsification. To explain progression in the stage process, univariate $F$-tests have been performed based on a large number of variables. The number of respondents is not indicated. The fact that no correlation matrix is presented makes it difficult to assess any spuriousness in the results. In explaining the movements from one stage to the next, some of the included variables - such as information seeking and local market orientation-may be epiphenomenal with the operationalization of the stage concepts, and thus represent tautologies. The cross-sectional design implies that the variables in fact cannot explain the process. Rather, they describe the firms belonging to the different stages. Czinkota's and Bilkey \& Tesar's Study. As noted above, Czinkota adapted the first four stages from the Bilkey and Tesar model. Czinkota [1982, p. 50] used the following (dichotomized) criteria to differentiate among international stages: Past export volume, absolute export volume, length of export experience, type of countries exported to, number of export customers, number of export transactions, and manpower committed to exporting. A set of null hypotheses about nine issues (each including several variables) were postulated to search for differences among the firms belonging to different stages. ANOVA was used to test differences among stages. However, no attempt was made to explain progression in the stage process.

In the Bilkey and Tesar study, the following (dichotomized) criteria were used to separate the stages: Past exporter, present exporter, exploration of exporting, filling of unsolicited orders, length of exporting experience, volume of export as percent of sales, and countries exported to. The number of firms classified at each stage is not stated. There are no arguments for the classification procedures. For instance, use of export experience for six years or longer and export value of $10 \%$ or more of total sales to classify a firm as an experienced exporter are not explained. Furthermore, there is no discussion of why and how the independent variables should influence the export development process. Nor does a complete list of included variables exist. These circumstances make it difficult to examine the work from a falsifiability perspective.

Each stage of the export development process was treated as a dependent variable in a multiple regression equation, and the independent variables were grouped into nonintercorrelated composites. The dependent variable was tested for each stage by means of a stepwise multiple regression analysis, adding variables as long as they improved the (unbiased) coefficient of multiple correlation. Results were only presented for firms that entered Stage 3, 4, and 5, respectively. The reasons for not testing a multiple regression equation between Stage 1 and 2, and between Stage 5 and 6 are not stated. 
FIGURE 5

A Brief Summary of the Evaluation from a Falsifiability Perspective

\begin{tabular}{l|l|l}
\hline $\begin{array}{l}\text { Aspects Evaluated } \\
\begin{array}{l}\text { Congruence between } \\
\text {-theoretical and } \\
\text { operational model } \\
\text {-conceptual and } \\
\text { operational definitions }\end{array}\end{array}$ & \multicolumn{1}{|c|}{ U-Model } & \multicolumn{1}{c}{ I-Models } \\
$\begin{array}{l}\text { Specification of variables } \\
\text { assumed to affect the } \\
\text { process development }\end{array}$ & $\begin{array}{l}\text { No variables beyond the } \\
\text { casual cycle model }\end{array}$ & $\begin{array}{l}\text { Some discrepancies in } \\
\text { Cavusgil's work } \\
\text { No validity tests }\end{array}$ \\
$\begin{array}{l}\text { Empirical setting } \\
\text { arguments for why and how } \\
\text { variables should } \\
\text { discriminate between stages } \\
\text { Cross-sectional studies, the } \\
\text { direction of causation } \\
\text { between export stage and } \\
\text { proposed determinants } \\
\text { unclear } \\
\text { In some cases, the } \\
\text { independent and dependent } \\
\text { variables are close to being } \\
\text { identical } \\
\text { Tautologies }\end{array}$ & $\begin{array}{l}\text { Case-study measurement } \\
\text { independent variable } \\
\text { observation of dependent } \\
\text { variable } \\
\text { Some difficulties in } \\
\text { delimiting the theoretical } \\
\text { concepts }\end{array}$ \\
$\begin{array}{l}\text { Test of alternative } \\
\text { explanatory variables }\end{array}$ & No &
\end{tabular}

From a methodological point of view, use of discriminant analysis would probably have been more informative than multiple regression.

In some cases, the independent and dependent variables are close to being identical. For instance, in analyzing the differences between Stage 1 and Stage 2 compared to Stage 3 (exploring the feasibility of exporting), one of the two significant independent variables turned out to be "whether or not management planned for exporting" (partial correlations=.447). Planning for exporting can be interpreted as a method of exploring the feasibility of exporting, leaving the explanatory value of this variable quite low.

Several of the included independent variables are composed of the management's expectations regarding the benefits of exporting, perceptions of barriers to exporting and evaluation of management quality. As long as the dependent variable divides the objects into various stages, the findings of differences between stages for these variables are practically tautological. As noted by Dichtl et al. [1984], "'managers who have committed themselves to exporting and actually engage in it, invariably take a more positive view on foreign operations and adhere to more export market planning than managers of non-exporting firms"' (p. 51). This problem will not be solved as long as cross-sectional designs are used.

Bilkey and Tesar's conclusion that the export development process of firms tends to proceed in stages (p. 95), should not be surprising as long as the 
firms in their cross-sectional study have been classified into different stages. Furthermore, Bilkey and Tesar's finding that firm size was relatively unimportant for export behavior when the quality and dynamism of management were accounted for, may have been influenced by the choice of classifying firm size into six categories instead of using the exact number of employees.

To summarize, the basic objection to the studies above is the lack of a proper design to explain the development process. Neither the criteria used to classify firms into stages nor why and how the independent variables should be able to discriminate between stages are properly grounded. In some instances, the independent and dependent variables are very close to being identical, and the direction of causation is not clear. On the operationalization level, no tests of validity or reliability, to ensure that a good measurement model has been reached, have been presented. The mode of presentation seems to be more aimed at verifying the assumed relationships (even if not always stated a priori), than at testing the relationships.

\section{CONCLUSIONS AND IMPLICATIONS}

Objections can be raised against making a critical analysis of models that emerged more than ten years ago. My defence is that these models have recently been repeated and modified (cf. Johanson and Vahlne [1990]), they seem to benefit from a general acceptance in the prevailing literature (e.g., Buckley [1991]), and they are still being used as a theoretical basis for empirical analyses (e.g., Dichtl et al. [1990]; Gripsrud [1990]; Czinkota and Ursic [1991]; Lim et al. [1991], Yang et al. [1992]). My purpose has been to illuminate the inherent weaknesses of the models, in order to stimulate further development and refinement. To my knowledge, no such coherent evaluation using scientific criteria has been presented, even though several authors have objected to some basic characteristics of the models (cf. Turnbull [1987]), and the boundary assumptions of the models (see, for instance, Engwall and Wallenstål [1988]; Forsgren [1989], Thomas and Araujo [1985]).

Although the evaluation is far from being complete, some basic measures should be obvious for improving the internationalization models. First, the delineation of theoretical boundaries, ensuring the explication of assumptions which bound the theory (values, scope, time) should be amplified. Johanson and Vahlne [1990] have contributed to this topic by observations about the relationships between and the different assumptions underlying their model and economics-based direct investment theory, but further efforts must be taken in this direction. For instance, is it possible to incorporate assumptions about decisionmakers being strategically conscious, acting on the basis of signals from the market and the competitors, when the purpose is to explain the early stages of the internationalization process?

Second, the models are lacking explanatory power. This implies vagueness in the purpose of the models. Why or how the process takes place or how 
to predict the movement from one stage to the next are not properly addressed. Little attention has been paid to the time dimension of the process. This is probably connected to the problem of delimitation between stages. Critical events of the firms' development and factors that affect the firms' export behavior should be identified. This should probably be conceived by different methods, including case studies. With further refinement and elaboration, Yang et al.'s [1992] concept of "market expansion ability" (which is based on the notion of organizational momentum) may turn out to be a promising concept to explain the internationalization process.

Third, more attention should be paid to the congruence between the theoretical and operational level. Too few attempts has been made to clarify the concepts and variables of the models at different levels of abstraction and the relationships that connect them. A requirement should be that theories or models should at least in principle meet the criterion of testability. Moreover, discussing and performing tests of different types of validity should have a high priority in the further development of the internationalization models.

Fourth, the empirical design must be adapted to the theoretical model. A cross-sectional design can neither document that firms proceed in stages, nor determine the factors that influence a firm's move from one stage to the next by using a cross-sectional design. Even though practical considerations render observation and analysis of firm behavior over time very difficult [Albaum and Peterson 1984], longitudinal analysis should at least be tried for small-sample studies in order to establish the stage models.

Finally, the internationalization process models represent a substantial and pioneering research in the field of international business. The U-model and I-models should have the potential to explain the initial stage of entry into international markets, provided that future research takes the measures outlined above.

\section{REFERENCES}

Albaum, Gerald \& Robert A. Peterson. 1984. Empirical research in international marketing 1978-1982. Journal of International Business Studies, 15 (Spring/Summer): 161-73.

Anderson, Erin \& Hubert Gatignon. 1986. Modes of entry: A transactions cost analysis and propositions. Journal of International Business Studies, 17 (Fall): 1-26.

Anderson, Paul F. 1986. On method in consumer research: A critical relativist perspective. Journal of Consumer Research, 13 (September): 155-73.

Ayal, Igal \& Joel Raban. 1987. Export management structure and successful high technology innovation. In Stan D. Reid \& Philip J. Rosson, editors, Managing export entry and expansion. New York: Praeger.

Bacharach, Samuel B. 1990. Organizational theories: Some criteria for evaluation. Academy of Management Review, 14(4): 496-515.

Benito, Gabriel R.G. \& Geir Gripsrud. 1991. The expansion of foreign direct investment by manufacturing companies: Discrete rational location choices or a cultural learning process? Paper presented at the European International Business Association Conference, Madrid.

Bilkey, Warren J. 1978. An attempted integration of the literature on the export behavior of firms. Journal of International Business Studies, 10 (Spring/Summer): 93-98. 
Bilkey, Warren J. \& George Tesar. 1977. The export behavior of smaller Wisconsin manufacturing firms. Journal of International Business Studies, 9 (Spring/Summer): 93-98.

Bradley, M. Frank. 1987. Nature and significance of international marketing: A review. Journal of Business Research, 15: 205-19.

1991. International marketing strategy. New York: Prentice-Hall, Inc.

Braybrooke, D. \& C.E. Lindblom. 1970. A strategy of decision. Policy evaluation as a social process. New York: The Free Press.

Buckley, Peter J. 1991. The analysis of international corporate strategy: An integrated framework and research agenda. In Harald Vestergaard, editor, An enlarged Europe in the global economy. European International Business Association, Proceedings of the 17th Annual Conference 1991, Copenhagen, Denmark.

G.D. Newbould \& J. Thurwell. 1979. Going international-The foreign direct investment behavior of smaller UK firms. In L.G. Mattson \& F. Wiedersheim-Paul, editors, Recent research of the internationalisation of business. Stockholm: Almquist and Wicksell.

Bunge, Mario. 1967. Scientific research. Vol. 2: The search for truth. New York: Springer-Verlag.

Calder, Bobby J., Lynn W. Phillips \& Alice M. Tybout. 1981. Designing research for application. Journal of Consumer Research, 8 (September): 197-207.

Calder, Bobby J. \& Alice M. Tybout. 1987. What consumer research is . . . Journal of Consumer Research, 14 (June): 136-40.

Caves, Richard E. 1982. Multinational enterprise and economic analysis. Cambridge: Cambridge University Press.

Cavusgil, S. Tamer. 1980. On the internationalization process of firms. European Research, 8 (November): 273-81.

1982. Some observations on the relevance of critical variables for internationalization stages. In Michael R. Czinkota \& George Tesar, editors, Export management: An international context. New York: Praeger.

\& John R. Nevin. 1981. State-of-the art in international marketing: An assessment. In Ben M. Enis \& Kenneth J. Roering, editors, Review in marketing. Chicago: American Marketing Association, 195-216.

Cavusgil, S. Tamer \& Yezdi M. Godiwalla. 1982. Decisions-making for international marketing: A comparative review. Management Decision, 20(4): 47-54.

Cook, Thomas D. \& Donald T. Campbell. 1979. Quasi-experimentation. Design \& analysis issues for field settings. Boston: Houghton Mifflin Company.

Cyert, Richard M. \& James G. March. 1963. A behavioral theory of the firm. Englewood Cliffs, N.J.: Prentice-Hall.

Czinkota, Michael R. 1982. Export development strategies: US promotion policies. New York: Praeger Publishers.

\&. Michael Ursic. 1991. Classification of exporting firms according to sales and growth into a share matrix. Journal of Business Research, 22(3): 243-53.

Dichtl, Erwin, M. Leibold, Hans-Georg Koglmayr \& Stefan Mueller. 1984. The export-decision of small and medium-sized firms: A review. Management International Review, 24(2): 49-60.

1990. International orientation as a precondition for export success. Journal of International Business Studies, 21(1): 23-41.

Dodd, S.C. 1968. Systemmetrics for evaluating symbolic systems. Systematics, 6: 27-49.

Douglas, Susan P., C. Samuel Craig \& Warren J. Keegan. 1982. Approaches to assessing international marketing opportunities for small and medium-sized companies. Columbia Journal of World Business, 17(3): 26-32.

Dunning, John H. 1988. The eclectic paradigm of international production: A restatement and some possible extensions. Journal of International Business Studies, 19(Spring), 1-31.

Engwall, L. \& M. Wallenstål. 1988. Tit for tat in small steps. The internationalization of Swedish banks. Scandinavian Journal of Management, 4(3/4): 147-55. 
Ford, David \& Leo Leonidou. 1991. Research developments in international marketing: A European perspective. In Stanley J. Paliwoda, editor, New perspectives on international marketing. London: Routledge.

Forsgren, M. 1989. Managing the internationalization process. London: Routledge.

Gatignon, Hubert \& Erin Anderson. 1988. The multinational corporation's degree of control over foreign subsidiaries: An empirical test of a transaction cost explanation. Journal of Law, Economics, and Organization, 4(2): 305-35.

Gripsrud, Geir. 1990. The determinants of export decisions and attitudes to a distant market: Norwegian fishery exports to Japan. Journal of International Business Studies, 21(3): 469-86.

Hennart, Jean-Francois. 1982. A theory of multinational enterprise. Ann Arbor: The University of Michigan Press.

Hunt, Shelby D. 1991a. Modern marketing theory: Critical issues in the philosophy of marketing science. Cincinnati, Ohio: South-Western Publishing Co.

1991b. Positivism and paradigm dominance in consumer research: Toward critical pluralism and rapporchement. Journal of Consumer Research, 18 (June): 32-44.

1992. For reason and realism in marketing. Journal of Marketing, 56 (April): 89-102.

Johanson, Jan \& Finn Wiedersheim-Paul. 1975. The internationalization of the firm-Four Swedish cases. Journal of Management Studies, 12(3): 305-22.

Johanson, Jan \& Jan-Erik Vahlne. 1977. The internationalization process of the firm-A model of knowledge development and increasing foreign market commitments. Journal of International Business Studies, 8 (Spring/Summer): 23-32.

1990. The mechanism of internationalization. International Marketing Review, 7(4): 11-24.

Kerlinger, Fred N. 1973. Foundations of behavioral research. London: Holt, Rinehart and Winston.

Lim, Jean-Su, Thomas W. Sharkey \& Ken I. Kim. 1991. An empirical test of an export adoption model. Management International Review, 31(1): 51-62.

Luostarinen, Reijo. 1980. Internationalization of the firm. Acta Academica Series A:30. The Helsinki School of Economics, Helsinki.

March, James G. \& Herbert A. Simon. 1958. Organizations. New York: John Wiley.

Papadopoulos, Nicolas. 1987. Approaches to international market selection for small- and mediumsized enterprises. In Stan D. Reid \& Philip J. Rosson, editors, Managing export entry and expansion. New York: Praeger.

\& Jean-Emile Denis. 1988. Inventory, taxonomy and assessment of methods for international market selection. International Marketing Review, 5 (Autumn): 38-51.

Peter, J. Paul \& Jerry C. Olsen. 1983. Is marketing science? Journal of Marketing, 47 (Fall): 111-25.

Popper, Karl. 1959. The logic of scientific discovery. New York: Harper and Row.

1983. Realism and the aim of science. The postscript to the logic of scientific discovery. In William W. Bartley, III, editor. Totowa, N.J.: Rowman \& Littlefield.

Reid, Stan D. 1981. The decision-maker and export entry and expansion. Journal of International Business Studies, 12 (Fall): 101-12.

1983. Firm internationalization, transaction costs and strategic choice. International Marketing Review, 1(2): 44-56.

\& Philip J. Rosson. 1987. Managing export entry and expansion: An overview. In Stan D. Reid \& Philip J. Rosson, editors, Managing export entry and expansion. New York: Praeger.

Rigby, Paul. 1965. Conceptual foundations of business research. New York: John Wiley and Sons, Inc.

Robertson, Thomas S. 1974. A critical examination of 'adoption process' models of consumer behavior. In Jagdish N. Sheth, editor, Models of buyer behavior. New York: Harper \& Row.

Rogers, Everett M. 1962. Diffusion of innovations. New York: The Free Press.

Root, Franklin R. 1987. Entry strategies for international markets. Lexington, Mass.: Lexington Books, D.C. Heath and Co.

Rugman, Alan M. 1982. New theories of the multinational enterprise. New York: St. Martin's Press. 
Simon, Julian. 1978 (second edition). Basic research methods in social sciences. New York: Random House.

Sternthal, Brian, Alice M. Tybout \& Bobby J. Calder. 1987. Confirmatory versus comparative approaches to judging theory tests. Journal of Consumer Research, 14(2): 114-25.

Stinchcombe, Arthur L. 1968. Constructing social theories. New York: Harcourt.

Sullivan, Daniel \& Alan Bauerschmidt. 1990. Incremental internationalization: A test of Johanson and Vahlnes's thesis. Management International Review, 30(1): 19-30.

Thomas, Michael J. \& Luis Araujo. 1985. Theories of export behavior: A critical analysis. European Journal of Marketing, 19(2): 42-52.

Turnbull, Peter W. 1987. A challenge to the stages theory of the internationalization process. In Stan D. Reid \& Philip J. Rosson, editors, Managing export entry and expansion. New York: Praeger.

Welch, Lawrence S. \& Finn Wiedersheim-Paul. 1980. Domestic expansion: Internationalization at home. Essays in International Business, No. 2. The University of South Carolina, December.

Welch, Lawrence S. \& Reijo Luostarinen. 1988. Internationalization: Evolution of a concept. Journal of General Management, 14(2): 34-55.

Wind, Yoram. 1979. The journal of marketing at a crossroad. Journal of Marketing, 43 (January): 9-12.

Yang, Yoo S., Robert P. Leione \& Dana L. Alden. 1992. A market expansion ability approach to identify potential exporters. Journal of Marketing, 56 (January): 84-96.

Young, Stephen, James Hamill, Colin Wheeler \& J. Richard Davies. 1989. International market entry and development. Englewood Cliffs, N.J.: Prentice-Hall.

Zaltman, Gerald, Christian R.A. Pinson \& Reinhard Angelmar. 1973. Metatheory and consumer research. Chicago, Ill.: Dryden Press. 